Session 2348

\title{
CENT 354 - Computer Architecture - A Project Class Using Cooperative Learning
}

\author{
Elmer A. Grubbs \\ The University of Southern Colorado
}

\section{INTRODUCTION}

CENT 354, a junior level course in the Electronic Engineering Technology (EET) and Computer Engineering Technology (CENT) department at the University of Southern Colorado, has been taught once a year for the last eight years. In its present form, it includes a substantial project, which involves building a four bit microprocessor using a XILINX XC3000 series integrated circuit and some external circuitry; the class also involves substantial collaborative learning and is taught using an active learning structure. Students who complete the course are able to design and build complex digital systems using the XILINX Design Manager, and in fact, one of the major outcomes is that students often use this field programmable gate array system in the design of their senior design projects.

This paper describes the microprocessor system, and the course structure in detail, including the techniques used in teaming, and active learning. It also includes a section on future improvements, such as a more comprehensive design project which is modeled more along the lines of an actual company project. This future structure would include oral proposals, design reviews, project management, larger design teams and more realistic purchasing department models.

\section{COURSE DESCRIPTION}

CENT 354, Computer Architecture, is a junior level required course in Electronics Engineering Technology (EET) at the University of Southern Colorado. It includes as prerequisites a course in Digital Logic (EET 254), and a basic course in Microprocessors (CENT 255). There are three hours of lecture each week and two hours of laboratory. The lab section has nine PC compatible 486, $66 \mathrm{Mhz}$ workstations with windows 3.1, allowing for 18 to 27 students, working in teams of two to three students each. The course has been taught each fall since 1989 .

The lecture section of the class consists first of a brief review of the digital and microprocessor courses, followed by a steered design of the basic components of a four bit microprocessor, which can solve a simple equation of the form $y=m x+b$. This involves presenting to the students techniques for designing the data components of a computer such as the accumulator, program counter, instruction register, bus structure, etc, as well as the control structure which is necessary to implement eight basic instructions. A block diagram of the data section and the list

of instructions is shown in figure one. The design of the control section is based on a 
synchronous clock with two phases, and comes directly from the timing diagrams of the various instructions. Following the steered design, an alternate approach using a Register Transfer Language (RTL) is presented to the students.

Next, several lectures on the contents of the basic building blocks of the XILINX field programmable gate array system are given. This is followed by a discussion of more general topics in computer architecture, such as parallel computing, memory organization, instruction set processing, etc.

The lecture involves using active learning and collaborative learning techniques. For example, after a short lecture on designing a two phase clock generator, the class is broken up into groups of two or three students each, and asked to redesign the clock generator, using the gray code. Typically, at the beginning of the semester, the students feel somewhat uncomfortable working in this mode. They tend to be very quiet and each works separately on the design. After some prodding, the students begin to work together. After a week or two, they quickly form their groups and the room is far from quiet as they collectively finish their assignments. It's a little difficult to break the habit of competing, but once they do, the learning seems far more enjoyable, and the students who were present during the active learning all were able to solve similar problems on the exams.

In addition, students were required to work in groups when doing homework, and in the laboratory section of the course. We have not yet tried the rather novel idea of taking exams in pairs, but several engineering education researchers have tried this with excellent success.

In the laboratory, the students start out slowly learning how to use the XILINX design system. It consists of a schematic capture program (PROCAPTURE), a simulator (PROSIM), a display program (PROWAVE), and two programs (XACT and PROFLOW) used to download the design into the field programmable gate array chip.

First, the class uses the schematic capture program to simply place an "AND" gate in the design. The circuit is simulated and the results displayed. Next, the process is repeated with a four flip flop ring counter. After that, the ring counter is placed and routed into the XILINX chip (XC3020-50), using the automated design program (PROFLOW). Then the students perform another simulation using this time the placed and routed design which includes actual delays for the various gates, instead of the zero delays used in the first simulation. Finally, the students investigate and use the design manager (XACT) to place and route the ring counter design. This allows them to use the full capabilities of the software, while at the same time requiring them to learn the rather intricate system in detail.

This section of the course, which takes about seven to eight weeks, is done in teams of two or three. For the remainder of the semester, the students continue to work in their teams on the actual design project, the design and construction of the four bit microprocessor. Adding to the complexity of the project is the construction of an interface board, which contains a key pad and a hex display, a load/run switch, as well as a reset switch and a clock. Please see figure two for a 
schematic of a typical project. Again the students display some reluctance to work in groups at first, but this quickly disappears as they progress into the second week of the lab.

\section{RESULTS}

Some major advantages of project classes and collaborative learning are: 1) students will undoubtedly work in teams on projects after they graduate, thus they will be far ahead of others who are still competing and working by themselves. 2) It will be easier to find employment if the student's resumes include project classes and teaming, as this is what industry is looking for in most cases. 3) Projects allow the students to practice all of the training and skills they have learned in school, not just selected ones from individual classes. 4) Teaming allows students to learn interpersonal relationship skills. 5) Projects give students the opportunity to learn how to find information in other places besides books and from instructors and to solve open ended problems. This again can be tough for the students to do when they first start; they expect the instructor to tell them everything and they don't quite know what to do when he/she doesn't, but they quickly learn to use other available resources (each other, former students, other instructors, company application departments, etc). 6). The instructor typically has less grading to do, as all homework, reports, etc. are done in teams, reducing the total number of items to be graded. 7) In collaborative learning situations, students learn from each other, making the learning seem less like work and more like fun.

The major disadvantages are: 1) Much more work needs to be done in setting up the projects, so that they can be described in terms of specifications that will actually work, and provide the student with a successful experience. 2) There will probably be some bad experiences caused by group members that can not get along with each other, or perhaps in one of the larger groups by a member who is not contributing. The second disadvantage causes concern, but is not unlike those problems in industry. Groups need to learn the techniques of solving interpersonal relationship problems, eventually, anyway. A member who is not contributing can be fired. He or she would then need to be hired by another group, or do the project by him or herself. In my classes the threat of being fired has been sufficient motivation to cause everyone to participate.

Thus far, the projects have, for the most part, been completed successfully. Each semester, the students tend to wait until the last several weeks to get started in earnest. Because of the giant time commitment needed at that time, some $(30 \%-40 \%)$ do not finish at the end of the semester and receive incompletes, with a penalty on the project for being late. Of those who do not finish during the semester, as many as one quarter never finish, and thus generally receive D's or failures in the class, since the project is worth $25 \%$ of the final grade.

The students generally appreciate what they learned in this class. The ability to actually finish a project of this magnitude is a major source of satisfaction for most students. The large design component of a project-based class is invaluable, particularly to the students when they graduate and go on to work for a company. Some students have actually received job offers, based almost exclusively on their participation in this class. 


\section{FUTURE WORK}

For the future, it would be nice to incorporate some ideas from previous courses at other institutions into this class. It will be organized more along the lines of a company, with each project group having three or four members, with one designated as the project leader. Formal project management theory will be introduced. The teacher will serve as the upper-level management contact. The purchasing department will have some stock available, but other parts will need to be ordered from manufacturers with the resultant associated time delays. The group will be responsible for an oral/written project proposal, a midterm oral/written design review and an oral/written final report. This more realistic structure should more properly help prepare the students for life in industry.

ELMER A. GRUBBS, Assistant Professor of Electronic Engineering Technology and Department Chair of Computer Engineering Technology, Computer Information Systems, and Electronic Engineering Technology, The University of Southern Colorado, Pueblo, Colorado.

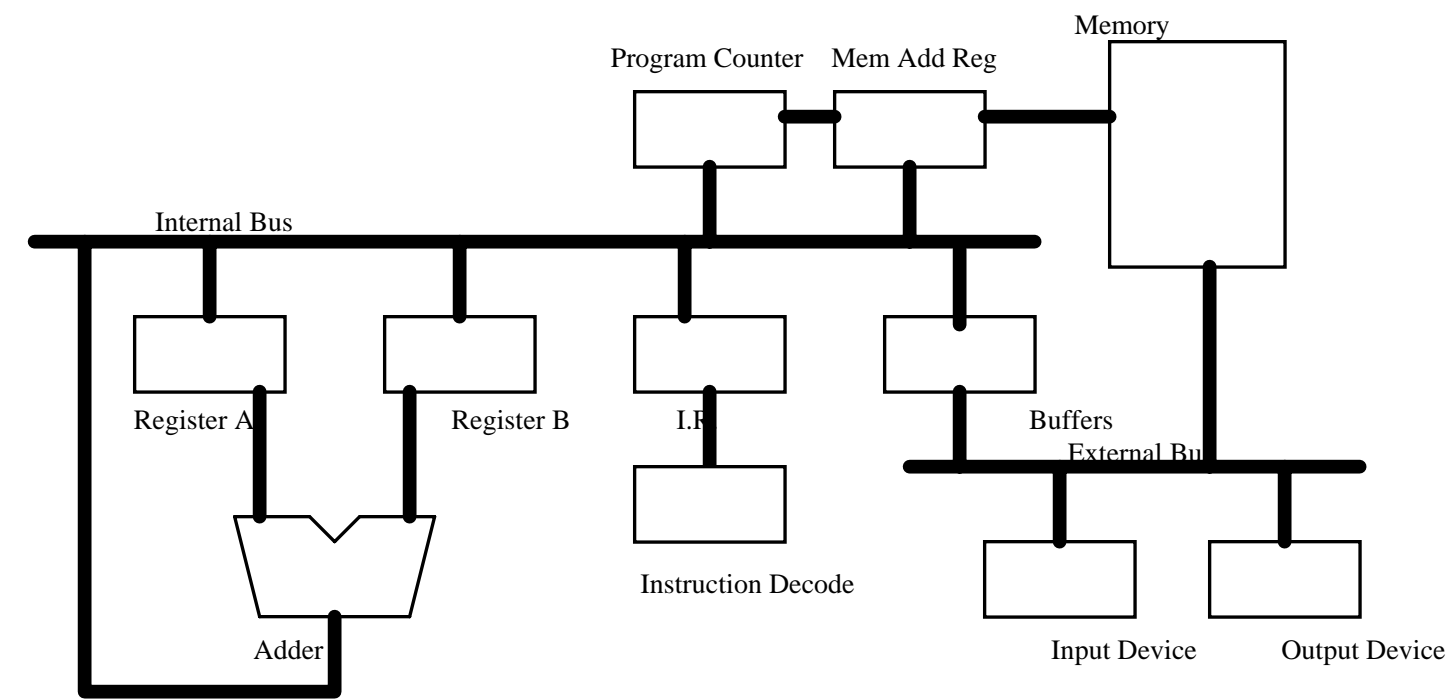

1. NOP

2. IN

3. ASL

4. ADD

5. OUT

6. STR

7. HLT

8. JMP

FIGURE 1 

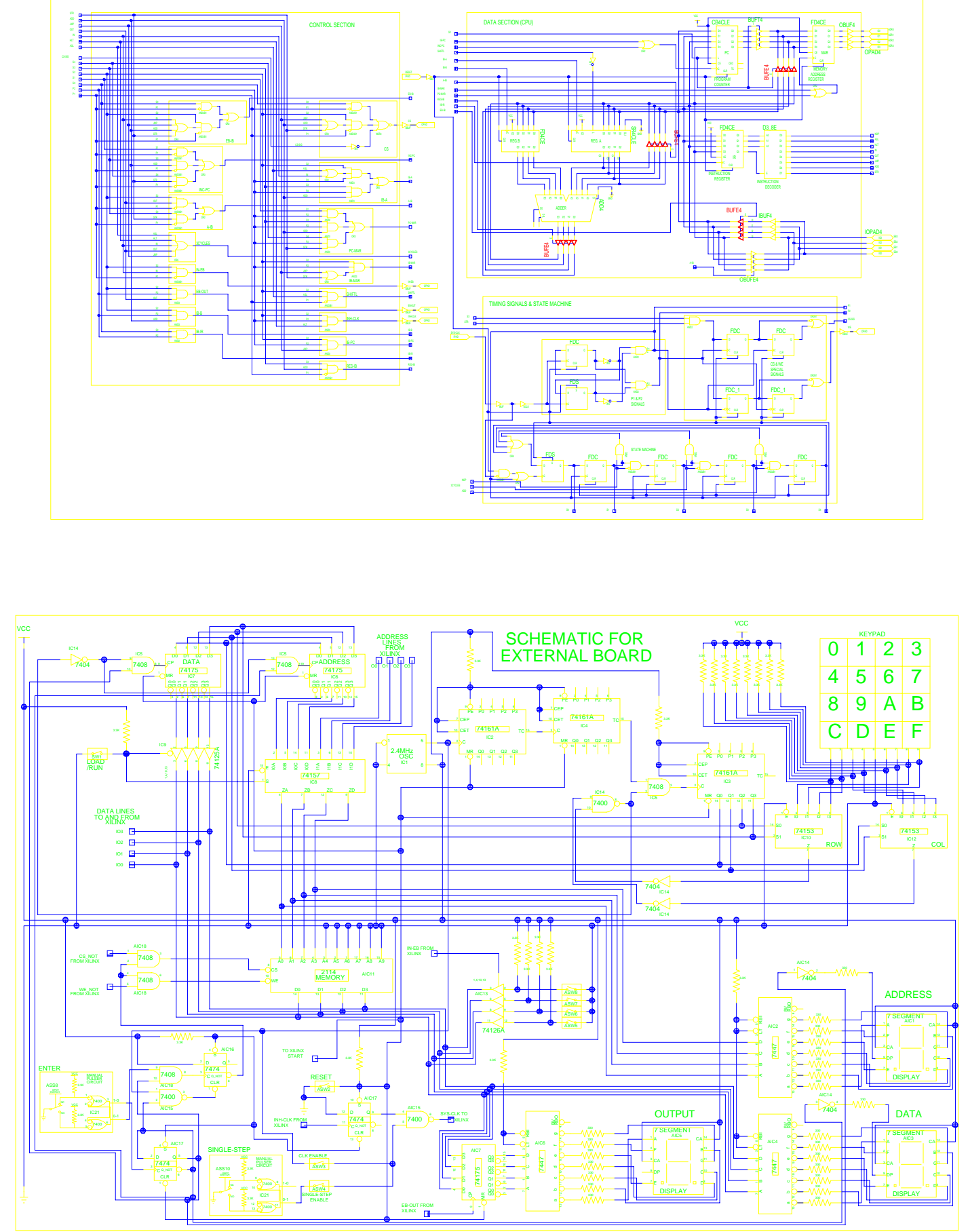

Figure 2

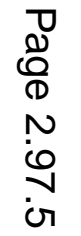

